\title{
Influence of Parenting Style and Peer Pressure on Adolescent Conflict with Parents in Ebonyi State
}

\author{
Dr. Athanatius Ifeanyi IBEH \\ Unugo, Louisa Obiageri \\ Department of Social Studies \\ Ebonyi State College of Education \\ Ikwo, Ebonyi State,Nigeria \\ Oriji, Sunday Anthony \\ Department of Integrated Science \\ Ebonyi State College of Education \\ Ikwo, Ebonyi State
}

\begin{abstract}
This study was designed to investigate the influence of parenting style and peer pressure on the adolescents' conflicts with parents in Ebonyi State. It is a descriptive survey guided by three research questions and three hypotheses all derived from the purpose of the study. The population of the study consists of all the Senior Secondary School SS2 adolescent students from all the 221 Secondary Schools in Ebonyi State. Using stratified sampling technique, nine (9) schools weredrawn from the entire population, three from each of the Education Zone. From this a sample of 200 students were purposively selected for the study; out of which 109 (54.5\%) adolescent males and 91 (45.5\%) adolescent female. Researcher developed instrument titled adolescent conflicts with parents questionnaire was used for data collection after its validation. Reliability coefficient of 0.62 was determined using Pearson product correlation formulae. Data was analyzed using mean and t-test for testing hypotheses at 0.05 level of significance. The findings include among others; there is significant difference between authoritative and permissive parents influence on prevalence of adolescents conflicts with parents; There is significant difference between peer and non-peer influence on prevalence of adolescent conflicts with parents Based on the findings, the researcher's recommended among other thing that; students should be provided with proper counseling especially on peer and group relationship to avoid conflict with parents; Parents are advised to reduce conflicts with their children by knowing when to be permissive and when to be authoritative, because life is about a little to the right and little to the left.
\end{abstract}

Keywords: Adolescent, Conflict, Parenting Style and Peer Pressure

\section{Introduction}

Adolescence is a period of psychological, social and intellectual transition. It is the period between the end of childhood and beginning of parenthood. Biologically it is a period of hastened physical and sexual maturation. Chronologically it comes between 11years and 17years of age. As a result of developmental changes that took place during this period, the adolescent becomes physically, socially and intellectually mature.

According to Agulanna and Anukogu, (1999) adolescence is a difficult time in the lives of young people both for themselves, their teachers, and parents. This period according to Agulanna and Anukogu, (1999) is mostly associated with conflict, turmoil and tension. It is common for parents to be demythologized in this period. The so called drive for freedom without responsibility plays a significant role during this period of adolescence (Craig, 2006). Empirical evidence indicates that many of today's adolescents have serious problems with drugs, alcohol, sex, etc., and that these problems are at least partly the result of stressful parent-adolescent relations (Dekovic 1999, Nordum 2002, Ikediashi, 2010).

According to Ikediashi, 2010), studies has shown that the widely held of arguments between parents and their adolescents are about normal, everyday, mundane family matters such as school work, social life and peers, home chores, disobedience, incongruities with siblings, values, perceptions, varied views, incompatible needs and personal hygiene. These types of arguments may be indicative of adolescents' growing desire for autonomy and independence from parents. 
Parents often hear children especially the adolescents; say words like "I can handle it; Daddy you won't understand; Sometimes parents discover that their children no longer accept rules and begin questioning and rebelling against parental authority. As children grow older, they are faced with the often awkward and challenging growth of their own autonomy. When adolescents begin to behave differently, adults think that this is a child's desire to form their own sense of independence or teenage rebellion. However, autonomy and independence may not be synonymous. According to Ikediashi, (2010), autonomy is larger in scope and includes an adolescent's capacity to think, feel, and act on his or her own; while independence involves personal behaviors on issues. Adolescents mostly are likely to argue, press for advantage, and test of the limits that parents set for them. This is because though adolescents are not fully grown adults, but they want to be treated as one. It is this transition between childhood and adulthood alongside physical and social changes bringing about changes in cognition including information processing which in effect increases the conflict between parents and their adolescent children.

Conflict on the other hand refers to some form of friction, or discord arising within a group when the beliefs or actions of one or more members of the group are either resisted by or unacceptable to one or more members of another group. Conflict can arise between members of the same group, known as intra-group conflict or it can occur between adolescence and their parents, members of two or more groups, and involve violence, interpersonal discord conflict. Conflict in groups often follows a specific course. Routine group interaction is first disrupted by an initial conflict, often caused by differences of opinion, disagreements between members, or scarcity of $r$ in some cases gives way to a conflict resolution stage, after which the group can eventuallyreturn to routine group interaction. Conflict is a common component of the parent-young adolescent relationship. Families with children entering adolescence can expect conflict about issues that recur but usually are not that "hot.It is very difficult to imagine a conflict free world and therefore, a conflict free organization as well as a conflict free family. Personalities are varied, the way we look at the world, our perceptions are different, our attitudes vary and what motivates us is different. This uniqueness is a major reason of the conflicts that we encounter in our personal, family as well as professional life.

According to AjaKpuru- Aja, Ndifon and Nwaodu (2013) conflict refers to physical skirmish, clash, controversy, hostility, tension, disagreement, competition, struggle among individuals and groups in a society. Conflict is a natural disagreement arising between two or more people. It exists when they have incompatible goals and one or more believe that the behaviour of the other prevents them from their own goal achievement.It is a process in which one party (person or group) perceives that its interests are being opposed or negatively affected by the other party.

According Sigmund Freud (1905/1962) and Stanley Hall (1904); regarded turbulent relations with parents as an unfortunate, but inevitable by-product of adolescent maturation. These early theorists states that; functional meaning of the different conflict produced during the adolescence period depends on the quality of the relationship between parents and their teenagers. Hence, the researcher will analyze this relationship taking into accounts the level of familiarity, fondness as well as communication. According to Cusinnto (1992), the conflicts between parents and adolescents are typical of the evolutionary process of transformation of relation produced in adolescence.

This period of human development according to Akinboye (2000) 'generally coincides with the secondary school level of education. It is a critical transition epoch between childhood and adulthood. On the frequency of conflict, Smetana and Asquitli (1994) revealed that adolescents rarely argue with their parents. However, research shows that the frequency and kind of conflict, differs depending on the sex of the parents and the teenagers. Therefore, authors like (Tierno, 1993; Noller1994) affirm that sons and daughters have more conflicts with mothers rather than with fathers. Moreover, the girls, especially with the arrival of puberty, have more conflicts with mothers than sons do. The research on conflicts between parents and adolescents varies. Some research affirms that conflicts between parents and adolescents start at the beginning of adolescence and they decline as the adolescents get older. (Dekovic, 1999; Smetana and Asquith, 1994) while other scholars (Cusinato 1992 and Montemayor, 1990) show that the conflicts raise till the first half of adolescence and from here they decline till the point of disappearing. Various investigations have found that these transformations can give rise to conflicts between parents and adolescents.

Actual studies reveal that adolescence is not such a troubled period as it was once though. In fact, a lot of boys and girls reach at adolescence without having a bad atmosphere with their families: they stay at home till an adult age. They also think in a similar way as their parents do and, in most cases, they feel satisfied, with the relations with their parent (Grotevant, 1989; Palacios, Hidalgo and Moreno, 1998). In this way, although adolescents start new relationships, they keep their family ties, which continue to be the main origin of support. In summary, it is safe to say that adolescents' and their parents are in conflict in all families some of the time and some families most of the time (Montemayor, 1983). This is because the psychological work of the adolescence period is to redefine the childish self into an adult self, which in effect makes the adolescent's conflict with parents inevitable. It is in this effect that the researcher is interested in analyzing the adolescent's conflicts with parents. 


\section{Statement of the Problem:}

The problem of this study is routed at the background of the study, therefore the main trust of this study is to determine the Influence of parenting style and peer pressure on the adolescents' conflicts with parents in Ebonyi State. It is in this regard that these questions readily come to the researcher's mind:

- Do conflicts occur more between the adolescent and their mother or father?

- Are these conflicts related to the adolescent's choice of peer-group?

- Are these conflicts related to the parenting style adopted by the adolescent's parents?

\section{Scope of the Study}

The scope of the study was to assess the extent of influence of Parenting style and Peer Pressure on adolescents' conflict with parent in Ebonyi State. This study is limited to Public- selected adolescents (in secondary schools) in Ebonyi State.

\section{Purpose of the Study}

The general objective of this study is to examine the influence of Parenting Style and Peer Pressure on Adolescents Conflicts with Parents. Specifically the objectives of the study will include:

- To determine if the adolescents conflicts with parents is influenced by the adolescents' peers.

- To determine if there is a link between the adolescents' conflicts with parents and the stage of adolescence

- To determine if these conflicts between adolescents and are in any way influenced by the parenting style

\section{Significance/Justification for the Study:}

The findings of this study will be of immense significant to the following stake holders in education: Parents, Teachers, Psychologists, Student counselors, Social Workers, Health Professionals, Sociologists, Psychiatrists, and other researchers in this field to help in the mediating process of adolescent conflict with parents

- To the Parents: The results of this research if published will act as an aid to the guidance of effective parenting skills that will enable parents to adequately deal with conflicts with adolescents when the need arises.

- The results of this research will be useful in planning and organizing necessary psychological support services for parents and adolescents in the country.

- Fellow researchers: The findings could aid other researchers to further evaluate the influence of Parenting Style and Peer Pressure on Adolescents conflict with Parents in other states other than Ebonyi State.

- The findings will serve as an information bases for Curriculum planners to actually enable them incorporate this aspect of societal issues in teaching and learning in our schools.

\section{Research Questions}

The following research questions guided the study

- What is the difference in means between authoritative and permissive parents score on their influence on prevalence of adolescents' conflicts with parents?

- What is the difference in means between peer and non-peer scores on their influence on prevalence of adolescent conflicts with parents?

- What is the difference in means between authoritative and authoritarian parents' scores on their influence on prevalence of adolescent conflicts with parents?

\section{Hypotheses}

The under listed null hypotheses were tested at 0.05 level of significance

Ho1:There is no significant difference between authoritative and permissive parents influence on prevalence of adolescent conflicts with parents.

Ho2: There is no significant difference between peer and non-peer influence on prevalence of adolescent conflicts with parents.

Ho3: There is no significant difference between authoritative and authoritarian parents influence on prevalence of adolescent conflicts with parents.

\section{Review of Related Literature}

\section{Conceptual frame work: Concept of Conflict}

Conflict is a recurring decimal in all human relationships. Conflictis a natural disagreement arising between two or more people. It exists when they have incompatible goals and one or more believe that the behaviour of the other prevents them from their own goal achievement. 
It is a process in which one party (person or group) perceives that its interests are being opposed or negatively affected by the other party. Conflict doesn't mean something is "wrong" in a relationship. It simply means that, for both parties, there is a difference in wants, values, perceptions, or a belief that needs to be declared, discussed, and resolved. Parent/child conflict increases during adolescence as the healthy teenager pushes for more independence to grow and healthy parents restrain that push in the interests of safety and responsibility.

The family, like any other modern institution or organization is not without potential negative features and incompatible behaviours which might be counterproductive and give rise to inefficiency or dysfunctional consequences in the achievement of goals and objectives. The family as an institution with division of labour, line of authority in terms of adolescents-parents subordinate-super ordinate relationships, rules and regulations and communication flow is bound to have conflicts which may result in deficiency in the performance of the family both in terms of discipline and academic proficiency (Uchendu, 2013).

According to AjaKpuru- Aja, Ndifon and Nwaodu (2013) conflict refers to physical confrontation, clash, controversy, hostility, tension, disagreement, competition, struggle among individuals and groups in a society.Conflict differs from competition, although competition may result in conflict. This means that conflicts may occur without any reference to competition as it could occur as a result of breakdown in the mechanism of decision making. Conflict occurs because individuals have different perceptions (Sagimo 2002, Rue \&Byarr 1992) it appears in variety of forms and grows from simple to complex, from non-violent to violent depending on the gravity, (Agenga\&Simawa 2011). Afful-Broni (2012) described conflict as a disagreement or incompatibility in wants, values and aspirations of two or more persons or group. It may also entail difference in people's opinions, beliefs and priorities. Owens (1987) believes that a conflict is a contest of opposing force or power; a struggle to resist or overcome. It is present whenever incompatible activities occur. Hellregle, Slocurn and Woodman (1992) are in agreement with Owens when they state that conflict refers to the situation in which there were incompatible goals, thoughts or emotions within or between individuals or groups which lead to bitterness and opposition. Conflict connotes a stressful, unhappy, distressing, depressing, annoying and frustrating state of affairs (Sagimo2002). Therefore, conflict is an inevitable friction in any organization and it exists at all levels of our families. Without doubt, no meaningful development can take place in a crisis-ridden family system torn apart by crisis as witnessed in the family institutions in the country today, (Adeyemi, Ekundayo and Alonge 2010). According to Carl Pickhardt(2013), below are some of the reasons for conflict

1. Each one is a unique personality.

2. Incompatible needs: Resources are limited but we need them at the same time and in maximum quantity.

3. Perceptions: We look at the same picture but with our own eyes.

4. Values: We value different things.

5. Beliefs are varied.

6. Cultural differences.

7. Job Design.

In the words of the researchers, they have this to say conflict is never one person's fault. It is both people's fault because conflict is always a cooperative act. It takes two to start it, maintain it, and conclude it. And conflict is never primarily about disagreement. It is always fundamentally about agreement. Conflict doesn't mean something is "wrong" in a relationship. It simply means that, for both parties, there is a difference in wants, values, perceptions, or a belief that needs to be declared, discussed, and resolved. Parent/child conflict increases during adolescence as the healthy teenager pushes for more independence to grow and healthy parents restrain that push in the interests of safety and responsibility.

\section{Concept of Adolescence:}

The term adolescence is derived from the Latin verb 'adolescere' which means to grow up or to grow into maturity. Hockenbury and Hockenbury (1997) defined adolescence as the transitional stage between late childhood and the beginning of adulthood. Erikson in Agulanna and Onukogu (2002) saw it as a period for the search for the self. It is the peak of human development such that if an individual is unable to form his ther ago identity or properly discover or define hislherself, the person will be swallowed up and will have defective personality development. Adolescence is a period of rapid development in the physical aspects such as height, hip, voice, strength etc.

\section{The Nature of Conflicts between Adolescents and Parents:}

The myth is that parents and teenagers do not like each other and do not get along with each other. The fact is that most adolescents feel close to and positive about their parents, have similar values on major issues/ and seek their parents' approval (Hill, 1987; Offer 1989). This does not, of course, mean that adolescents and their parents live in a calm, stress-free relationship. By and large, parents and adolescents do not clash over economic, religious, social, or political values. 
Most arguments are about mundane matters like schoolwork, chores, friends, dating, curfews, and personal appearance. Most disagreements are resolved with less trouble than popular mythology suggests. Quarrels may reflect some deep quest for independence (as is often speculated), or they may be just a continuation of parents' to teach children to conform to social rules. "This socializing task inescapably produces a certain amount of tension. At this point it is simply not clear whether parent-adolescent conflict has a 'deeper meaning' than this" (Montemayor, 1983). Research has shown that discord generally increases during early adolescence, stabilizes during middle adolescence, and then decreases after the young person is about 18 years of age. The increased conflict in early adolescence may be related more to puberty than to chronological age, and some intriguing new research suggests that it may even be bi-directional (Steinberg, 1988).

\section{Concept of Parenting Styles:}

Several researchers including Diana Baumrind (1991), Akinboye (2000) and Awoyemi (2002) have viewed parenting styles from different perspectives. According to Akinboye (2000) parenting styles vary from parent to parent, across cultures with religious beliefs of different orientations and varying theoretical orientations. He categorized parents into three groups regarding their parenting style.

The Winners: These parents chart an extreme parenting style which makes them strongly defend and persuasively justify their right to exercise authority or power over their child. This group of parents (Winner parents) uses threats of punishment to force obedience from the child and administers punishment when the child disobeys. When there is conflict between the needsof the parents and those of the child, the parents resolve the conflict in a way that they win and the child loses.

The losers: 'These parents allow their children a great deal of freedom all the time. They consciously avoid setting limits and proudly admit that they do' not accept the authoritarian style of parenting. When conflicts occur between the needs of the parents and those of the child, it is the child who consistently wins and the parent loses.

The oscillators: These parents find it impossible to follow either of the first two styles and as such oscillate between the winner and loser styles of parenting. They oscillate between being strict and lenient, tough and soft, restrictive and permissive. The oscillating parents according to Akinboye (2000.) are the most uncertain .and confused who produces the most quarrelsome children.

On the other hand Diana Raumrind (1991) believes that parents should be neither punitive nor aloof from their adolescents', but rather should develop rules and be affectionate with them. She emphasizes three types of parenting that are associated with different aspects of the adolescent's social behaviour and they are:

Authoritarian Parenting Style: these parents are restrictive, punitive, exhort the adolescents to follow their directions, respect work and effort, place limits and controls on the adolescent, and offer little verbal give and take between the adolescent and the parent. Authoritarian parenting is associated with these adolescent behaviours: anxiety about social comparison, failure to initiate activity and effective social interaction.

Authoritative Parenting Style: these parents encourage the adolescent to be independent but still places limits and controls on the adolescent's actions. Verbal give and take is extensive and parents are warm and nurturing towards the adolescent. This type of parenting is associated with the adolescent's social competence, especially self-reliance and social responsibility.

Permissive parenting Style; this is a style in which parents are uninvolved in their adolescent's life. These parents are neglecting and unresponsive. This type of parenting Baumrind says is consistently linked with a lack of self-control on the part of the adolescents. Parents of adolescents should learn the tactics of developing and sustaining trust in their relationships with their children, Trust is the basis of a beautiful relationship between the parent and the adolescent child; when trust is high, communication is easy, instant and effective. Effective communication is the key to effective parenting and resolving adolescents' conflict with parents.

\section{Concept of Peer Pressure:}

Involvement with one's peers and the attraction of peer identification increase as children grow, develop and move into early adolescence. As the adolescents grow, rapid physical, emotional and social changes occur and they begin to resist parental guidance and start questioning adult standards. They find it more reassuring to fall back to their peers for advice because they feel that they understand themselves better. According to Anukam and Anukam (2006), peers are the school mates or colleagues with whom the student interacts on a day-to-day basis in his academic pursuit. They are his closest physical neighbour while on campus; they are bound to wield a tremendous influence over his or her life" p. 41 . 
In a similar view, Burns and Darling cited in Ibeh (2015), states that a peer refers to anyone that one looks up to or who is an equal in age or ability to someone. A friend, someone in the school or community or even someone on a television programme could be a peer. Peers can be positive and supportive. They can help each other develop new skills, or stimulate interest in books, music or co-curricular activities. However, peers can also have a negative influence. One of the most striking features of adolescence is peer formation and peer pressure. It is also regarded as an emotional or mental force from people of the same social group (such as age, grade or status, political parties, trade union) to act or behave like themselves. The adolescent behaviour is greatly influenced by peer pressure. This influence is a reflection of the adolescent's desire to belong or to be accepted by his or her peers (w.w.w.rho.org/glossarg/htm). Based on the definition, the researchers conclude by saying that, peer pressure can be regarded as an emotional feeling or force by people of the same social group in order to behave alike.

\section{Theoretical Framework: The Psycho-Social Theories of Adolescence}

The theories in this category emphasize the social influence on the development of the adolescent. In other words these groups of theories believe that the influence of others on the development of the adolescent is significance. Prominent among them is Erik Erikson. Erik Erikson theory of adolescence is popularly known as Epigenetic model of identity formation. According to Erikson, a distinguished psychoanalyst considers adolescence as a particularly critical period for identity development which encompasses biological, social and individual components and contains. He holds that our understanding of personality development is derived from an epigenetic principle which states that "anything that grows has a ground plan, and that out of this ground plan, the parts arise, each part having its time of special ascendancy, until all parts have arisen to form a functioning whole" (Erikson 1968:92). He further states that any part that fails to ascend on time is doomed as an entity and the hierarchy to which it belongs is likely to be defective. For example at any stage of development of a person there are expected developmental tasks and characteristics for that stage genetically determined. These genetically determined tasks and characteristics represent the ground plan on which all other developments take root. It follows that if the characteristics to be developed at a particular period is disturbed and fails to manifest on time, it will be doomed and will not develop as it should be. Erickson in his epigenetic theory presents a picture of developmental process in eight (8) stages; four of which come before adolescences, while the other four come during adolescence. He further states that every stage of life signifies a new shift in instinctual energy, which gives impetus to new growth and awareness as encounters with the environment ensue. In other words, a present stage of development is a preparatory ground for a new stage as one uses the experiences on the present stage to leap into the subsequent stage(s) putting into consideration environmental forces.

Identity formation carries with it a mastery of the four childhood stages and a readiness to face the challenges of intimacy, generativity, and integrity in adulthood. From the presentations, the truth of the theory is that at adolescence, identity is the crucial characteristic to ascend or to establish, which invariably would influence the life of an adolescent now and in the future either negatively or positively depending on (1) His processes or style in his identity formation. (2) The social and environmental factors or forces that prevailed on him during the crucial period of identity formation, and (3) His adjustment and posture towards these social and environment forces. In fact, an attainment of a sense of identity gives impetus to prospective development of adulthood. From the foregoing, adolescents experience many changes as they make the transition from childhood to adulthood. Along -with physical and social changes come changes in cognition, or the way an individual thinks and processes information. As a result, there is often an increase in conflicts between parents and their adolescent children. Although it can be quite painful, an increase in conflict is part of normal development for adolescents (Tubman 1994), Conflicts usually pertain to chores, finances, appearance, and substance abuse (Galambos, 1992). Also, family relations, school, curfew, dating, (ends, and sexual behaviour causes disagreements between parents and their teenagers (Barber, 1994)

\section{Review of Empirical Studies:}

Holmbeck, (1995) carried out an investigation on Conflict with Parents and Gender of both the adolescent and parent. It was a descriptive survey. In one investigation of 64 high school students in the United States, interviews were conducted in their homes on three randomly selected evenings during a three-week period. The adolescents were asked about the events of the previous day, including any conflict they had with their parent. Conflict was defined as either you teased your parent or your parent teased you; you and your parent had a difference of opinion; one of you got angry at the other; you and your parent had a quarrel or an argument; or one of you hit the other. During the period of 192 days of tracking the 64 adolescents, an average of 68 arguments with parents was reported; this represented a rate of 0.35 arguments with parents per day or about one argument every three days. The ${ }^{1}$ average length of arguments was 11 minutes. Most conflicts were also found to be with mothers and the majorities were between mothers and daughters. 


\section{Method}

This study is a descriptive survey carried out in Ebonyi State. Ebonyi State is an inland south-eastern state of Nigeria. The state is situated in the south-eastern part of the country and shares boundaries with Benue to the north, Enugu to the northwest, Abia to the south-east and Cross River to the east. It has an area of 5,5333kmsq. Ebonyi state lies $6 \mathrm{deg} 15^{\prime} \mathrm{N}$, $8 \mathrm{deg} 05^{\prime} \mathrm{E} /$, 6.250degN, 8.083degE.(www.ngex.com/nigeria 29\10/2015). The population of the study consists of all the Senior Secondary School SS2 adolescent students from all the 221 Secondary Schools in Ebonyi State. Using stratified sampling technique, nine (9) schools were drawn from the entire population, three from each of the Education Zone. From this a sample of 200 students were purposively selected for the study; out of which 109 (54.5\%) adolescent males and 91 (45.5\%) adolescent female. Researchers developed instrument titled "Adolescents Conflicts with Parents Questionnaire" was used for data collection. It is a twenty-item test of a five-point Likert scale format with two sections. The first section presents the Adolescents Personal data to which subjects were expected to fill in as appropriate. The second section presents twenty value statements to which subjects were expected to rank order their values. The instrument was used to obtain necessary information on Adolescents Conflicts with Parents.

The questionnaire instrument was sent for validation in Department of Education Psychology, Guidance and Counseling, Measurement and Evaluation and validity was ascertained by assessing the items to ensure that the instrument measured the content and face validity of the variable understudy. In order to establish the reliability of the instrument, it was pretested with, a pilot sample of 25 students who were later post-tested five weeks later. The reliability coefficient was determined with the use of the Pearson's Product Correlation formula of both the pre-test and post-test scores of the students. The reliability coefficient based on the test-retest of the pilot sample was 0.62 . The researcher administered the instrument using Direct Delivery Technique (DDT) with the help of three well trained research assistants, each from the three Education Zones in the State. Each research assistant covered his or her own education zone. The criterion measure or dependent variable was adolescents conflicts with parents while the predictor or independent variables were; gender, parenting style and peer pressure. The research questions and hypothesis were answered using mean and t-test statistical analysis. The level of significance used was 0.05 level for the entire hypothesis tested.

\section{Data Presentation and Analysis of Results}

Research Question 1: What is the difference in means between Authoritative and Permissive Parents score on their influence on prevalence of adolescent conflict with parents.

Table 1.Difference in mean between authoritative and Permissive Parents score on their influence on prevalence of adolescent conflict with parents

\begin{tabular}{lcc}
\hline $\begin{array}{l}\text { Parental } \\
\text { Style }\end{array}$ & $X$ & $\begin{array}{c}\text { Difference in } \\
\text { Mean }\end{array}$ \\
Authoritati & $\mathbf{5 4 . 0 0}$ & \\
ve & & \\
Permissive & $\mathbf{5 9 . 7 4}$ & $\mathbf{5 . 7 4}$ \\
\hline
\end{tabular}

Table 1 above shows that the difference in means authoritative and Permissive Parents is (5.74) and is on the side of permissive parents. This indicates that permissive parents perpetuate prevalence of adolescents' conflicts with parents' more than authoritative parents.

\section{Research Question 2}

What is the difference in means between peer and non-peer score on their influence on prevalence of adolescent conflict with parents?

Table 2.Difference in mean between peer and non-peer on prevalence of adolescent conflict with parents

\begin{tabular}{lcc}
\hline Peer & $X$ & $\begin{array}{c}\text { Difference in } \\
\text { Mean }\end{array}$ \\
Peer & $\mathbf{5 9 . 9 5}$ & \\
$\begin{array}{l}\text { Non- } \\
\text { peer }\end{array}$ & $\mathbf{5 6 . 7 1}$ & $\mathbf{3 . 2 4}$ \\
\hline
\end{tabular}

Table 2 shows that the difference in means peer and non-peer adolescent scores is (3.24) and is on the side of peer group. This indicates that peered adolescents perpetuate prevalence of adolescents' conflicts with parents more than peer free adolescents. 


\section{Research Question 3}

What is the difference in means of authoritarian and authoritative parents score on their influence on prevalence of adolescent conflict with parents?

Table 3.Difference in mean between authoritarian and authoritative parents on prevalence of adolescent conflict with parents

\begin{tabular}{ccc}
\hline $\begin{array}{c}\text { Parental } \\
\text { style }\end{array}$ & $X$ & $\begin{array}{c}\text { Difference in } \\
\text { Mean }\end{array}$ \\
$\begin{array}{c}\text { Authoritaria } \\
\text { n }\end{array}$ & $\mathbf{5 4 . 0 0}$ & \\
$\begin{array}{c}\text { Authoritativ } \\
\text { e }\end{array}$ & $\mathbf{5 8 . 4 7}$ & $\mathbf{4 . 4 7}$ \\
\hline
\end{tabular}

Table 3 shows that the difference in means between authoritarian and authoritative parents' scores is (4.47) and is on the side of authoritative parents. This indicates that authoritative parents perpetuate prevalence of adolescents' conflicts with parents' more than authoritarian parents.

Hypothesis One: There is no significant difference between authoritative and Permissive parents influence on prevalence of adolescent conflict with parents.

Table4. Result of t-test analysis testing the null hypothesis that authoritative and Permissive parents influence on prevalence of adolescent conflicts with parents

\begin{tabular}{ccccccccc}
\hline Variable & $\mathrm{N}$ & $\mathrm{X}$ & $\mathrm{SD}$ & $\mathrm{df}$ & $\mathrm{L} s$ & $\begin{array}{c}\text { Pro } \\
\mathrm{b}\end{array}$ & $\begin{array}{c}\text { t-computed t-critical } \\
\text { Decision }\end{array}$ \\
Authoritati & & $\mathbf{5 4 . 0}$ & $\mathbf{2 . 2}$ & & & & & \\
ve & $\mathbf{4 0}$ & $\mathbf{0}$ & $\mathbf{2}$ & & $\mathbf{0 . 0}$ & $\mathbf{0 . 0}$ & $\mathbf{5 . 9 9}$ & $\mathbf{1 . 9 6}$ \\
Permissive & $\mathbf{6 8}$ & $\mathbf{5 9 . 7}$ & $\mathbf{5 . 8}$ & $\mathbf{1 0 6}$ & $\mathbf{5}$ & $\mathbf{0}$ & \multicolumn{2}{c}{ Reject } \\
\hline
\end{tabular}

Table 4 shows that $\mathrm{t}$-computed (5.99) is greater than t-critical (1.96), and the level of significance $(0,05)$ is greater than the Prob (0.00). This result rejects the null hypothesis and accepts the alternate hypothesis that there is significance difference between authoritative and Permissive parents influence on prevalence of adolescent conflicts with parents.

Hypothesis Two: There is no significant difference between peer and non-peer influences on prevalence of adolescent conflict with parents.

Table 5. Result of t-test analysis testing the null hypothesis that there is no significant difference between peer and non-peer influence on prevalence of adolescent conflicts with parents

\begin{tabular}{|c|c|c|c|c|c|c|c|c|c|}
\hline Variable & $\mathrm{N}$ & X & $\mathrm{SD}$ & df & Ls & $\begin{array}{c}\text { Pro } \\
\mathrm{b}\end{array}$ & $\underset{\mathrm{d}}{\mathrm{t}-}$ & \multicolumn{2}{|c|}{$\begin{array}{l}\mathrm{t} \text {-critical } \\
\text { Decision }\end{array}$} \\
\hline $\begin{array}{l}\text { Peer } \\
\text { Non- } \\
\text { Peer }\end{array}$ & 80 & $\begin{array}{c}59.9 \\
5 \\
56.7 \\
1\end{array}$ & $\begin{array}{c}4.9 \\
1 \\
5.0 \\
2\end{array}$ & 198 & 0.05 & 0.00 & 4.52 & 1.96 & Reject \\
\hline
\end{tabular}

Table 5 shows that t-computed (4.52) is greater than t-critical (1.96), and the level of significance (0.05) is less than the Prob (0.00). This result rejects the null hypothesis and accepts the alternate hypothesis that there is significance difference between peer and non-peer influence on prevalence of adolescent conflicts with parents.

Hypothesis three: There is no significant difference between authoritarian and authoritative parent influence on prevalence of adolescent conflict with parents

Table 6. Result of t-test analysis testing the null hypothesis that there is no significant difference between authoritarian and authoritative parent on prevalence of adolescent conflicts with parents

\begin{tabular}{|c|c|c|c|c|c|c|c|c|c|}
\hline Variable & $\mathrm{N}$ & $X$ & SD & df & Ls & & & $\begin{array}{c}\mathrm{t}- \\
\text { critical }\end{array}$ & $\begin{array}{c}\text { Decisio } \\
\mathrm{n}\end{array}$ \\
\hline $\begin{array}{c}\text { Authoritar } \\
\text { ian } \\
\text { Authoritati } \\
\text { ve }\end{array}$ & 92 & $\begin{array}{c}54.0 \\
0 \\
58.4 \\
7\end{array}$ & $\begin{array}{l}2.22 \\
4,79\end{array}$ & 130 & 0.05 & 0.00 & 5.63 & 1.96 & Reject \\
\hline
\end{tabular}


Table 6 shows that t-Computed $(5,63)$ is greater than t-critical $(1,96)$, and the level of significance $(0.05)$ is greater than the Prob (0.00). This result rejects the null hypothesis and accepts, the alternate hypothesis that there is significance difference between authoritarian and authoritative parents influence on prevalence of adolescent conflicts with parents.

\section{Summary of Findings}

From the analyses above, the following findings were made:

- There is significant difference between authoritative and permissive parents influence on prevalence of adolescent conflicts with parents.

- There is significant difference between peer and non-peer influence on prevalence of adolescent conflicts with parents.

- There is significant difference between authoritative and authoritarian parents influence on prevalence of adolescent conflicts with parents.

\section{Discussion}

The answer to the first research question shows that male adolescent perpetuate conflicts with parents more than their female counterparts. Similarly, result of the first hypothesis indicate that there is significance difference between male and female adolescent influence on prevalence of adolescent conflicts with parents; Thus the gender (male of an adolescent may serve as a criterion to conflicts with his parent, because male adolescent at this stage of their development thirst for freedom without responsibility, while their parents want control and perhaps wants to set limits for the adolescent child. The male adolescents are more rebellious than their female counterparts. This generally brings about conflicts with parents. So this is to say that an adolescent male regardless of the gender is predisposed to having increased conflicts with parents. The result of these findings is in line with the works of Smetana and Asqulth (1994) who postulated that the frequency and kind of conflicts differs depending on the gender of the adolescent. The second research question and their hypothesis are interested in whether the difference between authoritative and permissive parents influences the prevalence of adolescent conflicts with parents. Results presented in table 4.3 and 4.9 indicate that there is significant difference between authoritative and permissive parents influence on prevalence of adolescents conflicts with parents. Thus permissive parents perpetuate prevalence of adolescents' conflicts with parent's more than authoritative parents. These types of parents according to Baumrind (1990) are neglecting and unresponsive and this type of parenting type is consistently linked with a lack of self-control on the adolescent. The third research question and the fourth hypothesis are interested "in where there is a significant difference between peer and non-peer influences on prevalence of adolescents' conflicts with parents. Result presented in table 4.4 and 4.10 indicate that there is significant difference on prevalence of adolescent conflicts with parents. Thus peered adolescent perpetuate prevalence of adolescent conflicts with parents more than peer free adolescents. This finding is line with the works of Steinberg and Morris (2001) who affirm that adolescents appear most influenced by peers during the adolescent period.

The result of these findings was not in agreement with the work of Brown (1990) who postulated that adolescents see their relations with their parents as supportive thereby becoming more socially competent and more likely to report positive peer relationship. He went on to say that peer influence is strongest in relatively superficial matters such as preferences for music and clothing styles, and beliefs about how late to stay out at night. In conclusion, it is clear that these differences between peers and parents can contribute to increased conflict in the family. And parents who were once practically the sole influence on their children can feel their authority is threatened and that their ability to raise their adolescents as they fit is compromised by peer influences. The third research question and research hypothesis is interested in whether there is a significant difference between authoritative and authoritarian parents influence on prevalence of adolescent conflict with parents. Results indicate clearly that there is significant difference between authoritative and authoritarian parents influence on prevalence of adolescent conflict with parents. Thus authoritative parents perpetuate prevalence of adolescent conflicts with parents' more than authoritarian parents. Though parents who practice the authoritative style of parenting encourage the adolescent child to be independent they still place limits and control the adolescent actions (Baumrind 1990).

\section{Conclusion}

In conclusion, the study shows that the adolescents' conflict with parents has a direct relationship with peer pressure. On the other hand, the study reveals that the adolescents' conflict with parents has direct relationship with the parenting styles adopted by the parents. 


\section{Recommendations}

- The researchers recommended that, since peer relations serves as a source of affection, sympathy and understanding for the groups, parents should seriously keep a watchful eye on the type of relationships their adolescent children keep at this stage of life.

- The researchers also recommended that students should be provided with proper counseling especially on peer and group relationship to avoid conflicts with parents.

- There is need for proper upbringing of children and wards by parents and guardians.

- Parents are advised to reduce conflicts with their children by knowing when to be permissive and when to be authoritative. Because life is about a little to the right and little to the left.

- Stay away from peers who pressure you to do things that seem wrong or dangerous

\section{References}

Adesina O.A. 1988. The Development of Modern Education in Nigeria.Lagos: Heinomaun.

Adesina S. 1983. Secondary Education in Nigeria, lle-lfe: University Press.

Agulanna, G. G. and Nwachukwu, F.J. 2007.Psychology of Learning, Dotting theory into practice; Owerri, Career Publishers.

Agulanna, G. G. and Onukogu, C.J. 1996. Psychology: An Introductory Survey, Benin, BarlozPublisers Inc.

AjaAkpuru-Aja, Ndifon, C.O. and Nwaode, N.O. 2013. Law, Conflicts and Human Rights in Africa (Peace Studies Series) Nigeria: CHCDSS.

Akinboye, J.O. 2000. Parenting success.A seminar paper presented at the department of guidance and counselling, University of Ibadan. Pp 7-11.

Alade A. O. 1998. Conflict Management within the Nigeria Baptist Convention, unpublished Ph.D thesis, University of Ibadan.

Awoyemi, A. E. 2002. The concept and nature of parenting and parenting styles.A seminar paper presented at the department of guidance and counselling, University of Ibadan, Pp3-7."

Baumrind, D. 1978. Parental disciplinary patterns and social Competence in children. Youths and society.9: 239 276.

Baumrind, D. 1991. Effective parenting during the early adolescent transition. In P.A Cowan \& E.M. Hetherington (Eds). Advances in family research, (Vol. 2. Hillsdale, NJ: Eribaum.

Burber, U.K. 1994.Cultural, family, and person contexts of parent-adolescent conflict.Journal of Marriage and the Family, 56, 375-1 386.

Carl Pickhardt(2013)"SURVIVING YOUR CHILD'S ADOLESCENCE" (Wiley, 2013.) Also my book about family conflict, "Stop the Screaming." Information at: www.carlpickhardt.com (link is external)

Campbell, R. F, Carbally, J. E, and Nustrand, R. O. 1983.Introduction to Educational Administration (6th edition. Boston: Allyn and Bacon Inc.

Craig, C. T. 2006. Human Development, New York Prentice Hall Inc.

Dekovic, M. 1999. Risk and Protective Factors in the Development of Problem Behaviour during.Adolescence.Journal of Youth and Adolescence, 28 (6): 667 - 685.

Erikson. E. H. 1968. Identity, Youth Crises, New York, Norton Press.

Fadipe J. O. 2000. Efficiency Indicators for Quality Control in Nigeria, Journal of NIEPA, Ondo Nigeria.

Gardiner, P. D. and Dimons J. E. 1992. The Relationship Between Conflict, Change and Project Management, London.

Holmbeck, G. 1995. Conflictive engagement, positive affect, and menarche in families with seventh-grade girls.Journal of Child Development, 62,1030-1048.

Ibeh, A.I.(2015), Family Climate,Peer Pressure and Cognitive Learning skills As Correlates of Students Academic Achievement in Social Studies in Ebonyi State, Nigeria. Ph.DDissertation, Imo State University, Owerri.

IKediashi, A.E. 2008.Patterns of antisocial behaviours among Adolescent Secondary School Students.Nigeria Journal of Counselling and Consulting Psychology, 9 (2) Dec. pp 131- 142.

IKediashi, A.E. 2010. The Problems of Nigerian adolescent: A search for a realistic approach. International Journal for Interdisciplinary I Social Science, Vol 7 pp 102 - 110. May 2010.

IKediashi, A.E. and Iroegbu T.C. 1998.Determinants of behaviourand learning, Owerri.Cape Publishers.

Kandel, D. B. 1986. Processes of peer influences in adolescence. In R.K. Silbereisen, K. Eyferth\& G. Rudinger (Eds), Development as action in context: Problem behaviour and normal youth development: Berlin; SpringerVerlag. 
Kandel, D. B. and Lesser, G. S. 1972. Youth in two worlds: United States and Denmark. San Francisco: Jossey Bass Publishers.

Mangel, S. K. 2010. Essentials of educational psychology. New Delhi Phi Learning Private Ltd.

Miller E. C. and King M. E. 2005.A Glossan of Years and Concepts in Peace and Conflict Studies Addis Ababa, University of Peace African Programme.

Montemayor, R. 1983. Parents and adolescents in conflict: All families come of the time and some families most of the time. Journal of Early Adolescents, 3, 83- 10.

Montemayor, R. and Hanson, S.(1985. The relationship between parent-adolescent, conflict and amount of time adolescents spend alone with parents and peers. Child Development, 53, 1512-1519.

Steinberg, L. 1988. Family Structure and the Development of Autonomy During Adolescence Journal of Early Adolescence, 13, $38-55$.

Uchendu C. C. Amijaobi Idem, F. N. and Odigwe, F. N. 2013.Conflict Management and Organizational Performance in Secondary Schools in Cross River State, Research Journal in Organizational Psychology and Educational Studies Vol. 2. 